\title{
MigraÇão VenEZuelana no JoRnAL NACIONAL
}

\author{
Valéria Marcondes \\ Faculdade de Ciências Sociais Aplicadas, Universidade do Oeste de Santa Catarina, Brasil
}

Moisés de Lemos Martins

Centro de Estudos de Comunicação e Sociedade, Instituto de Ciências Sociais, Universidade do Minho, Portugal

\begin{abstract}
ReSUMo
Com o propósito de explorar os sentidos narrativos, este artigo analisa o discurso do Jornal Nacional (JN), da Rede Globo, sobre os venezuelanos deslocados para o Brasil, em decorrência da crise econômica, política e social em curso na Venezuela. Definimos como recorte temporal 17 edições de 2018 , que enquadraram a presença de imigrantes venezuelanos no Brasil. À luz da Sociologia compreensiva identificamos nós cegos nas práticas discursivas do JN. A chegada dos imigrantes é narrada como uma ameaça à normalidade e à estabilidade. A perpetuação deste regime discursivo pode funcionar como um mecanismo de exclusão, gerador de novos medos e inseguranças.
\end{abstract}

\section{Palavras-chave}

jornalismo; silenciamentos; imigrantes; exclusão social; Venezuela

\section{VENEZUELAN MIGRATION IN JORNAL NACIONAL}

\begin{abstract}
This article analyzes the discourse of Jornal Nacional (Globo Channel) about Venezuelans displaced to Brazil as a result of the economic, political and social crisis in Venezuela, in order to explore their narrative senses. We decided to use, as a temporal cut-off, 17 editions of 2018 , with an analytical emphasis on those that showed the presence of Venezuelan immigrants in Brazil. With the help of Sociology, we identified the blind nodes in the discursive practices of Jornal Nacional. The arrival of the immigrants is narrated as a threat to normality and stability. The perpetuation of this discursive regime may function as a mechanism of exclusion, generating new fears and insecurities.
\end{abstract}

\section{KEYWORDS}

journalism; silencing; immigrants; social exclusion; Venezuela

\section{Textos E CONTEXTOS}

Os grandes movimentos migratórios atuais devem-se à miséria, perseguição política, conflitos bélicos, crises econômicas, questões climáticas. Não é de hoje que os homens migram para fugir da fome, das guerras, dos riscos ambientais. Podemos retomar 
a expansão europeia, dos séculos XV e XVI, e a colonização de continentes que se the seguiu, ou restringir-nos às grandes guerras mundiais do século XX. Em termos sociais, a Europa de hoje está em transformação graças às migrações, não apenas de sírios e africanos, que fogem dos conflitos bélicos, mas mesmo de europeus que migram devido a motivações econômicas, buscando melhores oportunidades profissionais e qualidade de vida, por exemplo. Quanto à América Latina, foram a colonização e os movimentos migratórios, incluindo milhares de refugiados, os responsáveis pela sua forma social.

Historicamente, os seres humanos buscam além-fronteiras a dignidade não encontrada em suas nações de origem. Imigrantes e refugiados, no entanto, são vistos de forma distinta. Segundo respondentes de uma pesquisa realizada com 16.040 pessoas em diversos países, nem todos os refugiados precisavam realmente fugir de seus países de origem. $61 \%$ dos inquiridos, entendem que terroristas estão infiltrados em grupos de refugiados (Buarque, 2016). Após a divulgação desta pesquisa, a ONU, por meio do porta voz da Acnur, "alertou contra a demonização dos refugiados".

A ONU (Malik, 2014, p. 213) conceitua refugiados como

pessoas que fugiram do seu país de origem devido a um receio de perseguição fundamentado em razão da sua raça, religião, nacionalidade, opinião política ou pertença a um grupo social específico e que não podem ou não desejam regressar ao seu país de origem.

Bauman $(2004,2016,2017)$ pensou o desperdício das vidas teorizando sobre o refugo na sociedade atual, referindo-se à questão migratória na Europa. Identificou o medo que se sente dos refugiados como uma ameaça existencial. A diferença é percebida como risco ao modo de ser europeu, uma ameaça à identidade europeia. O autor fala na indústria do medo, produzido pelo próprio sistema e critica a salvação vinda do poder do Estado.

Anteriormente, Bourdieu (1998, p. 11) descreveu o não-lugar dos imigrantes:

atopos, sem lugar, deslocado, inclassificável (...). Nem cidadão nem estrangeiro, nem totalmente do lado do Mesmo, nem totalmente do lado do Outro, o "imigrante" situa-se nesse lugar "bastardo" de que Platão também fala, a fronteira entre o ser e o não-ser social. Deslocado, no sentido de incongruente e de importuno, ele suscita o embaraço; e a dificuldade que se experimenta em pensá-lo (...). Incômodo em todo lugar e que doravante tanto em sua sociedade de origem quanto em sua sociedade receptora, ele obriga a repensar completamente a questão dos fundamentos legítimos da cidadania e da relação entre o Estado e a Nação ou a nacionalidade. Presença ausente, ele nos obriga a questionar não só as reações de rejeição, que ao considerar o Estado com uma expressão da Nação, justificam-se pretendendo fundar a cidadania na comunidade de língua e de cultura (quando não de raça), como também a "generosidade" assimilacionista que, confiante em que o Estado, armado com uma educação, saberá produzir a Nação, poderia dissimular um chauvinismo do universal. 
Voltando à América Latina, a Organização dos Estados Americanos (OEA, 2017, p. 13) publicou, em dezembro de 2017, estudo sobre a situação dos direitos humanos na Venezuela, no qual denuncia a debilidade da democracia, o aumento da repressão, a violência e a insegurança, apontando a "grave crise política, econômica e social que atravessa o país nos últimos dois anos", "caracterizada pelo desabastecimento generalizado de alimentos, medicamentos, tratamento, material a consumo médico, dentre outros. Precisamente em 2015, registrou-se um aumento de 180,9\% nos preços, e em abril de 2016, 80\% da população enfrentava escassez de alimentos" (OEA, 2017, pp. 22-23).

$\mathrm{Na}$ abordagem do estudo da OEA (2017, p. 17), a crise na Venezuela

constitui uma problemática complexa que tem raízes na ingerência do Poder Executivo sobre os outros poderes públicos. Esta inobservância do princípio de separação de poderes se reflete de maneira particularmente grave na preocupante atuação do Poder Judicial, em especial nos dois últimos anos. Como efeito, o agravamento da crise recente na Venezuela se relaciona estreitamente com uma série de decisões adotadas pelo Supremo Tribunal Justiça (STJ), que representam ingerências na Assembleia Nacional (AN) e afetaram o princípio de separação de poderes. Esta situação se agravou em 2017 a ponto de produzir-se uma alteração da ordem constitucional.

Boaventura de Sousa Santos (2017, s.p.) comenta sobre o processo em curso naquele país, as interferências externas, relembra a "tentativa de golpe de Estado em 2002 "protagonizada pela oposição com o apoio ativo dos Estados Unidos", que, em 2015, declarou considerar a Venezuela como "ameaça à segurança nacional dos Estados Unidos".

Os efeitos da crise econômica mundial e o abalo no setor petrolífero em 2009 tiveram efeitos, inclusive na Venezuela. Logo após a sucessão do socialista de cariz bolivariano (Botelho, 2008; Lopes, 2013; Schurster \& Araujo, 2015), Hugo Chávez (1999 a 2013), por Nicolás Maduro, num processo eleitoral acirrado que fortaleceu a oposição, houve, em 2014, outra queda do valor do barril do petróleo no mercado internacional.

Novamente, Boaventura de Sousa Santos (2017, s.p.) contextualiza:

a situação passou a piorar, até que, em dezembro de 2015, a oposição conquistou a maioria na Assembleia Nacional. O Tribunal Supremo de Justiça suspendeu quatro deputados, alegando fraude eleitoral, a Assembleia $\mathrm{Na}$ cional desobedeceu. A partir daí, a confrontação institucional se agravou e foi progressivamente se espalhando pelas ruas, alimentada também pela grave crise econômica e de abastecimento que eclodiu no país. Mais de cem mortos, uma situação caótica.

Estes fatos terão contribuído significativamente para que a Venezuela iniciasse um processo de desestabilização da economia, que conduziu o país à hiperinflação, 
desabastecimento de itens básicos, escassez de alimentos. As reservas de petróleo da Venezuela - recurso estratégico para o país - são de interesse internacional, principalmente de potências neoliberais como os Estados Unidos.

Preocupado com as interferências externas na Venezuela, Sousa Santos (2017, s.p.) reforça:
a história recente mostra que as sanções econômicas afetam mais aos ci- dadãos inocentes do que aos governos. Basta lembrar das mais de 500 mil crianças que, segundo o relatório das Nações Unidas de 1995, morreram no Iraque como resultado das sanções impostas depois da Guerra do Golfo. Recordemos também que na Venezuela vivem meio milhão de portugueses ou lusodescendentes. A história recente também ensina que nenhuma de- mocracia sai fortalecida de uma intervenção estrangeira.

Um milhão de venezuelanos deixaram o seu país entre 2014 e 2017, de acordo com o Alto Comissariado das Nações Unidas para os Refugiados'. O Ministério da Justiça (2017b, s.p.) brasileiro relata o panorama regional do refúgio nas Américas:

entre janeiro e setembro/2017, cerca de 48.500 venezuelanos solicitaram refúgio no mundo, quase o dobro do ano anterior. Até julho de 2017, estimava-se que havia cerca de 300.000 venezuelanos na Colômbia, 40.000 em Trinidade e Tobago, e 30.000 no Brasil em situações migratórias diversas ou em situação irregular.

Quanto à imigração de venezuelanos ao Brasil, o Ministério da Justiça (2017a, s.p.) informou que houve um aumento significativo nos pedidos de refúgio de venezuelanos entre 2010 e 2016 . Neste ano, foram 3.375 solicitações - cerca de $33 \%$ de todos os registros no país em 2016. Em 2015, 829 venezuelanos entraram com pedido de refúgio. Em sua conclusão, o documento citava os "cinco países com maior solicitação de refúgio em 2016: Venezuela, Cuba, Angola, Haiti e Síria". Ou seja, a situação não é obra do acaso.

No período analisado neste artigo, o Jornal Nacional (JN) optou por silenciar o fato de que outros países da América Latina estão recebendo venezuelanos. O G1 Roraima publicou uma reportagem em $02 / 03 / 2018 \mathrm{com}$ dados que poderiam ter sido utilizados pelo Jornal Nacional (Costa \& Brandão, 2018). "Os venezuelanos também vão à Colômbia, Peru, Equador, Chile, Argentina e Uruguai", informa o professor José Franco. Ele explica que primeiro vinham venezuelanos de classe média e depois os das classes mais populares. Segundo o JN, edição de 10/03/2018 ${ }^{2}$, entre janeiro e fevereiro de 2018 , 24.466 venezuelanos pediram para entrar no Brasil pelo posto da Polícia Federal de Roraima - número quase três vezes maior do que no mesmo período de 2017. Dada a ênfase noticiosa, o discurso demonstra que a vinda de venezuelanos de classe média

\footnotetext{
' Informação retirada de http://www.unhcr.org/publications/fundraising/5aobfffo7/unhcr-global-appeal-2018-2019-americas.html

${ }^{2}$ Começa a campanha de vacinação contra o sarampo em Roraima (10 de março de 2018). Jornal Nacional. Retirado de https://globoplay.globo.com/v/6569499/programa/
} 
ao Brasil não representa ameaça, quando comparado à chegada de venezuelanos de camadas mais pobres da sociedade. Este "regime do olhar" perpetua um discurso de não aceitação e a impossibilidade de convivência, que se processa por meio da sensibilização centrada na unidade e não na alteridade (Martins, 2011, 2019).

O levantamento do Conselho Nacional de Imigração, divulgado em setembro de 2017 pela ACNUR, detalha o perfil sociodemográfico e laboral dos imigrantes venezuelanos no Brasil:

$72 \%$ dos venezuelanos não-indígenas são jovens entre 20 e 39 anos, a maioria do sexo masculino (63\%) e solteiros (54\%). Praticamente um em cada três $(32 \%)$ tem curso superior completo ou pós-graduação, enquanto três em cada quatro (78\%) têm nível médio completo. Entre os não-indígenas, $82 \%$ já apresentaram pedido de refúgio. Nesse caso, cerca de $1 / 3$ deles têm o protocolo de refúgio, $23 \%$ possuem carteira de trabalho, $29 \%$ têm CPF e $4 \%$ não possuem nenhum documento. ${ }^{3}$

Estes dados não foram, todavia, assinalados pelo JN.

Roraima é apenas a porta de entrada, apesar de muitos venezuelanos optarem por ali se estabelecer, dada a proximidade com seu território de origem. $\mathrm{Na}$ leitura do JN, e segundo fontes oficiais da prefeitura de Boa Vista e do governo de Roraima, lá se instalou o caos, por causa da migração em massa de venezuelanos, e o poder público federal pouco faz para resolver a situação.

O Estado enfrenta problemas logísticos e não consegue oferecer condições dignas de alojamento aos imigrantes, apesar dos repasses de recursos federais. Roraima já decretou diversas vezes estado de emergência social, solicitando reforço das forças armadas para controle da fronteira e assistência à saúde. A imigração não é caótica, como parecem expressar os discursos analisados. O número de venezuelanos no Brasil "é considerado baixo em termos absolutos, quando comparados com o tamanho da população do Brasil, a extensão territorial e a realidade de outros países de porte semeIhante", como refere Camila Asano, Coordenadora do Programa da ONG Conectas Direitos Humanos, em entrevista ao jornal Nexo (Charleaux, 2018). De acordo com Camila Asano "todos os imigrantes, regulares e irregulares, correspondem hoje, no Brasil, a 1\% da população total do país. Nos EUA, é 14\%. Na Argentina, 4\%. O Brasil recebe pouco e poderia receber muito mais". A coordenadora afirma que "é a falta de respostas adequadas aqui que dá a sensação de crise no Brasil".

\section{O discurso do JN PELO viés dA Sociologia COMPREENSIVA}

A Sociologia compreensiva permitiu analisar o regime discursivo sobre os refugiados. Nela, o discurso é compreendido como exercício de poder simbólico (Bourdieu, 1989), interiorizado pelo dominante e pelo dominado como violência simbólica, dentro

3 Informação retirada de http://www.acnur.org/portugues/noticias/noticia/maioria-de-venezuelanos-em-roraima-e-jovem-possui-boa-escolaridade-e-esta-trabalhando/ 
de um campo social e num contexto de relação concretas, de emissores e receptores legítimos, segundo rituais legítimos e aceitáveis. É no discurso que o indivíduo se distingue. Usa a linguagem para ser percebido. Também os discursos midiáticos estão inscritos nesse regime de funcionamento dos sistemas simbólicos (Martins, 2015).

No âmbito dos conceitos de campo e habitus, Bourdieu entende as representações como construções coletivas e históricas que precedem o indivíduo, ou seja, já existem na estrutura da sociedade, sendo todavia reformuladas pelo indivíduo através da linguagem com a qual se constrói uma visão de mundo particular, influenciada pela posição social que se assume, orientando suas práticas sociais.

Weber (2004/1922, p. 191) compreende dominação como

uma situação de fato, em que uma vontade manifesta ("mandado") do "dominador" ou dos "dominadores" quer influenciar as ações de outras pessoas (do "dominado" ou dos "dominados"), e de fato as influencia, de tal modo que estas ações, num grau socialmente relevante, se realizam como se os dominados tivessem feito do próprio conteúdo do mandado a máxima de suas ações de obediência.

Eagleton (1997, p. 83), a partir de Bourdieu, descreve a legitimação da dominação: "um tipo de dominação costuma legitimar-se quando as pessoas submetidas a ela chegam a julgar sua própria conduta pelos critérios dos seus governantes". Assim, das representações, julgamentos, preconceitos, valores, percepções, capitais simbólicos, presentes nas estruturas cognitivas, interiorizados no habitus, derivam práticas sociais (discursos e ações).

A Sociologia da Comunicação (Berkowitz, 1997; Breed, 1997; Schudson 1986, 1988; Sousa Santos, 2000; Traquina, 2001; Tuchman, 1978) e as noções de campo e habitus (Bourdieu, 1978, 1989, 1998) permitem compreender as notícias como resultantes de um processo de construção simbólica, no qual estão envolvidos aspectos sociais, cognitivos, culturais, cujos produtores pertencem a uma comunidade jornalística e estão inseridos num contexto organizacional, numa dada sociedade. Também nos discursos midiáticos encontramos demonizações, silenciamentos, ideologias, valores das organizações jornalísticas, dos poderes instituídos e das fontes, evidenciados na reconstrução dos acontecimentos ordenados pela estrutura da notícia.

Em pesquisa de maior escopo, analisámos as edições de 2017 e 2018 do Jornal Nacional sobre a Venezuela. A coleta foi realizada entre fevereiro e março de 2018 , no portal Globo Play - Jornal Nacional 4 -, via cadastro de assinante, por meio da identificação dos vídeos postados pelo JN entre 2017 e 2018, cujos títulos identificassem o tema Venezuela. Ao todo, tratou-se de 50 matérias em 2017 e 21 matérias entre um de janeiro e 20 de março de 2018. Dada a limitação de espaço, no presente artigo, apresentamos a análise do conteúdo de 17 matérias, do total das 21, apresentadas entre cinco de janeiro e 20 de março de $2018^{5}$.

\footnotetext{
${ }^{4}$ Retirado de https://globoplay.globo.com

${ }^{5}$ Excluimos da análise duas notas peladas (apenas texto) e duas notas cobertas (com áudio e vídeo).
} 
O Jornal Nacional levou ao ar, em 26 de janeiro de $2018^{6}$, uma reportagem relativa ao agravamento da crise, após o governo Maduro rejeitar a candidatura de chapa opositora à disputa eleitoral, antecipada para abril. O JN informa que a comunidade internacional (nomeadamente EUA, Grupo de Lima, Espanha) condenou a convocação do pleito. Não há posicionamento de fontes do governo venezuelano. A crise na Venezuela é enquadrada de modo a que o público naturalize a ideologia do próprio JN. A ideologia é aqui entendida enquanto produto coletivo e coletivamente apropriado, servindo a interesses particulares que tendem a apresentar-se como interesses universais (Bourdieu, 1989). Não há outras explicações sobre os motivos que levaram à crise econômica.

No mês de fevereiro7, o Jornal Nacional veiculou matérias focadas nos "problemas" enfrentados pelo Estado de Roraima "por causa dos venezuelanos", incluindo a volta do sarampo, trazido "por venezuelanos não vacinados", e nas ações do governo brasileiro e de Roraima para controlar a entrada e a interiorização destes imigrantes.

$\mathrm{O}$ ataque a imigrantes venezuelanos foi destaque em chamada do JN e posterior nota coberta, de 08/02/2018. Afirmando que a "polícia investiga ataques com gasolina a duas casas de imigrantes venezuelanos em Boa Vista", é apresentado o relato de uma vítima e destacado outro ataque em que criança de três anos e o pai ficaram feridos. Foram dois casos em três dias. Uma comitiva do governo federal esteve em Roraima para tratar da "imigração em massa de venezuelanos que fogem da crise". O JN informa que 40 mil venezuelanos estão vivendo em Boa Vista. Dentre as medidas adotadas pelo Palácio do Planalto, estão o reforço do policiamento da fronteira, a revalidação de diplomas de médicos e professores venezuelanos e o projeto para levar imigrantes para outros estados (interiorização). Em nota coberta de 09/02/20189 , o JN afirma que, segundo a polícia, uma mesma pessoa - cujo nome não foi divulgado - seria responsável pelos dois ataques. Crimes foram registrados por câmera de vigilância. Diversas organizações assinaram nota de repúdio à xenofobia em Roraima.

Uma reportagem de 12/02/2018 ${ }^{10}$ aborda a reunião entre o Presidente Temer e autoridades do Estado de Roraima, na qual decidiram pela criação de força-tarefa para tratar do problema de imigrantes venezuelanos no Estado. Segundo o jornal, Temer solicitou controle das fronteiras e criou um gabinete federal para acompanhar as ações e a realização de censo para saber o número exato de venezuelanos. O Presidente afirmou

\footnotetext{
${ }^{6}$ Justiça da Venezuela barra aliança da oposição (2018, 26 de janeiro). Jornal Nacional. Retirado de https://globoplay.globo. com/v/6452910/programa/

7 Calil e Barboza (2018) vinculam o aquecimento do debate em redes sobre imigrantes venezuelanos e o fortalecimento desta pauta na agenda midiática a dois fatores: "o desfile do Grupo Especial das escolas de samba do Rio (...) e a viagem do presidente Michel Temer, durante o feriado de Carnaval, a Roraima. (...) o debate passa a incorporar, de forma centralizada, a conjuntura de chegada e recepção dos imigrantes na fronteira do país". Retirado de http://dapp.fgv.br/ analise-de-redes-sobre-refugiados-venezuelanos-aponta-para-o-desafio-migratorio-em-roraima/

${ }^{8}$ Casas de imigrantes venezuelanos em Boa Vista são incendiadas (2018, 8 de fevereiro). Jornal Nacional. Retirado de https://globoplay.globo.com/v/6487662/programa/

${ }_{9}$ Casas de venezuelanos em Boa Vista foram atacadas pela mesma pessoa, diz polícia (2018, 9 de fevereiro). Jornal Nacional. Retirado de https:/globoplay.globo.com/v/6491024/programa/

10 Temer anuncia força-tarefa para tratar de imigrantes venezuelanos (2018, 12 de fevereiro). Jornal Nacional. Retirado de https://globoplay.globo.com/v/6497344/programa/
} 
que o Exército estará à frente das ações junto ao governo do Estado de Roraima. Temer editaria medida provisória para destinar "todos os recursos necessários para solucionar a questão dos venezuelanos em Roraima". Como ocorre em outras matérias, o JN apresenta números: são 40 mil venezuelanos morando na capital. Só em janeiro, 15.108 pediram para entrar em Roraima pela fronteira. Eles fogem da fome e do desemprego, repete o JN.

Dentre os destaques apresentados no início do JN de 15/02/2018" está: "o Brasil adota medidas para dar assistência a venezuelanos que chegam a Roraima". A reportagem fala do decreto de emergência social no Estado e do envio de 30 homens da força nacional para ajudar o controle da fronteira. Foca também na campanha de vacinação de imigrantes. "Em busca de remédio para malária, venezuelana chora agradecida pelo atendimento. A Venezuela sofre de surto de doenças como sarampo" - um caso confirmado de sarampo em bebê de um ano que morava em Boa Vista. A repórter afirma que desde 2015 não havia registro da doença no Brasil. Venezuelana conta que no país vizinho não tinha vacina de graça e agora se sente protegida. Presidente Temer assinou medida provisória, com ações emergenciais para acolher imigrantes, decreto criando comitê federal para monitorar a situação e outro decreto, ainda, reconhecendo a vulnerabilidade de Roraima "por conta da intensa imigração de venezuelanos". Em Boa Vista vivem 40 mil venezuelanos, finaliza a matéria.

Roberto Burnier conduz uma reportagem (16/02/2018) ${ }^{12}$ em Boa Vista. Da praça central Simon Bolívar - "ponto de encontro de venezuelanos", inicia relato detalhado, sensibilizando para a miséria e pobreza em que vivem atualmente. Explica que a hiperinflação do país vizinho passa de dois mil por cento ao ano. Burnier mostra as filas de venezuelanos, em busca da solicitação de status de refugiado. "Como se não bastassem todos esses problemas, o sarampo - doença erradicada no Brasil desde 2016 - voltou". Ingrid, imigrante que mora na praça há um mês, diz: "não quero que me tragam comida. Quero um trabalho para poder ganhar".

Numa chamada de destaque do JN de 17/02/201813 é referido: "nossos repórteres vão à fronteira com a Venezuela e mostram que nada mudou com a decretação de emergência social em Roraima, por causa da onda de imigrantes que fogem da crise no país vizinho". Burnier entrevista Carmem que migrou há três anos. Está aqui porque precisa de trabalho. "Não há comida na Venezuela. Não há nada", relata Carmem. O Programa de assistência emergencial aos imigrantes prevê

medidas de proteção social nas áreas de infraestrutura, saúde e educação, mas na pequena Pacaraima venezuelanos dormem nas ruas. Alguns tentam emprego no município, mas a maioria vai para Boa Vista. Na fronteira,

\footnotetext{
"Governo federal decreta emergência social em Roraima (2018, 15 de fevereiro). Jornal Nacional. Retirado de https://globoplay.globo.com/v/6506359/programa/

${ }^{12}$ Roraima começa a vacinar imigrantes venezuelanos contra o sarampo (2018, 16 de fevereiro). Jornal Nacional. Retirado de https://globoplay.globo.com/v/6509642/programa/

${ }^{13}$ Venezuelanos chegam todos os dias para buscar refúgio no Brasil (2018, 17 de fevereiro). Jornal Nacional. Retirado de https://globoplay.globo.com/v/6511798/programa/
} 
alguns venezuelanos fazem câmbio paralelo entre o real e o bolívar - atividade ilegal e clandestina. Não há fiscalização. Cambistas agem livremente. ${ }^{14}$

Burnier conversou com agente da Polícia Federal que

não pode ser identificado. Ele disse que, apesar de Temer ter decretado estado de calamidade social no estado, por enquanto, nada mudou no controle da fronteira. 30 militares da Força Nacional de segurança já estão em Pacaraima, mas até agora não começaram a atuar. O Governo Federal afirmou que o decreto de situação de emergência social não fecha a fronteira, mas disponibiliza recursos. Diz que a Polícia Federal e o Exército já dobraram o efetivo no Estado e que na segunda mais efetivo chegará a Roraima. ${ }^{15}$

A migração venezuelana ao Brasil nos é contada pelo JN através de repetições e reforços discursivos: "aumento vertiginoso", "onda de imigrantes" venezuelanos que fogem da fome, do desemprego, dos altos preços dos itens básicos, da "gravíssima crise política, econômica e social". Resumindo do ponto de vista do JN, os venezuelanos fogem do modelo socialista bolivariano de Hugo Chávez, perpetuado por Nicolás Maduro. Com efeito, na abordagem do Jornal Nacional, a crise política é anterior à crise econômica e social. A entonação de William Bonner na abertura da reportagem de 19/02/2018 ${ }^{16}$, e o uso de adjetivo superlativo, revela que:

a crise econômica, social e política da Venezuela, gravíssima, produziu onda imigratória no norte do Brasil. Todos os dias chegam 800 venezuelanos ao Estado de Roraima. Em Boa Vista, eles ainda dependem de ajuda de voluntários para ter o que comer.

Burnier mostra crianças "lutando contra a fome", o "desespero" atrás de comida e a gratidão dos venezuelanos aos voluntários que distribuem comida e sobra das refeições. O jornalista ressalta: enquanto Maduro estiver no governo, Iris não volta pra Venezuela. José lembra que estava passando fome no país vizinho.

Burnier reforça que "muitos venezuelanos cruzam a pé os 220 quilômetros para chegar ao Brasil pelo município de Pacaraima. A ajuda humanitária prevista no decreto assinado semana passada só deve começar na quinta desta semana"17. General do Exército Gustavo Dutra afirmou que a força-tarefa logística e humanitária atuará recebendo, cadastrando e também precedendo com a interiorização de imigrantes.

\footnotetext{
14 Venezuelanos chegam todos os dias para buscar refúgio no Brasil (2018, 17 de fevereiro). Jornal Nacional. Retirado de https://globoplay.globo.com/v/6511798/programa/

${ }^{15}$ Venezuelanos chegam todos os dias para buscar refúgio no Brasil (2018, 17 de fevereiro). Jornal Nacional. Retirado de https://globoplay.globo.com/v/6511798/programa/

${ }^{16}$ Por dia, 800 venezuelanos entram no Brasil pela cidade de Pacaraima (RR) (2018, 19 de fevereiro). Jornal Nacional. Retirado de https://globoplay.globo.com/v/6515990/programa/

17 Por dia, 800 venezuelanos entram no Brasil pela cidade de Pacaraima (RR) (2018, 19 de fevereiro). Jornal Nacional. Retirado de https://globoplay.globo.com/v/6515990/programa/
} 
Em "Filhos da imigração", reportagem que foi ao ar em 20/02/201818, Bonner qualifica e caracteriza a imigração escolhendo agora o adjetivo "vertiginoso" para relatar os problemas enfrentados por Roraima, apoiando-se, novamente na metáfora da força da natureza: a "onda imigratória de venezuelanos pro Brasil, produziu um aumento vertiginoso nos atendimentos no Sistema Público de Saúde de Roraima, principalmente de um tipo específico de procedimento". Burnier revelará o suspense: só em Roraima, 150 venezuelanas deram à luz no mês de janeiro - são os "filhos da imigração Venezuela". "E esse número deve aumentar. É cada vez mais comum venezuelanas grávidas cruzando a fronteira com o Brasil". A reportagem apresenta dados de partos de venezuelanas em Roraima: em 2016 foram 288, em 2017, 572 partos. Em 2018, uma média de cinco partos por dia. Muitas grávidas moram nas praças de Roraima e chegam à maternidade desnutridas. A quantidade de bebês prematuros é enorme, ressalta Burnier. O diretor da maternidade, confirma a preocupação do jornalista.

Outra situação "comum" apresentada pelo JN em tom de ameaça e iminência de caos no atendimento público de saúde do Estado de Roraima, são as venezuelanas habitantes de Santa Elena - município do país vizinho - que cruzam a fronteira para dar à luz em Roraima, pois "lá a situação é muito precária". Muitas dessas mulheres não voltam à Venezuela. Com filhos brasileiros, a cidadania é garantida, explica fonte da OAB de Roraima, contextualizando que estas mães não precisam encaminhar processo de solicitação de refúgio.

Nota pelada de 21/02/2018 19 noticia em 15 segundos que governo brasileiro vai começar a transferir imigrantes venezuelanos de Roraima - a chamada interiorização. São Paulo e Amazonas serão os primeiros Estados a receber estrangeiros que "fogem da crise gravíssima no país vizinho". Em 23/02/201820, o JN reproduz, em nota coberta, defesa da OEA para que Venezuela adie as eleições presidenciais e conte efetivamente com a participação de todos os partidos políticos.

A imigração venezuelana é destaque dentre as chamadas no início da edição de 26/02/201821. Em nota coberta, o JN anuncia o controle da entrada de venezuelanos em Pacaraima por 100 homens do Exército: "só este ano, 18 mil venezuelanos entraram no Brasil fugindo da fome e da crise política no país deles. No fim de semana, quase 600 foram cadastrados para deixar Roraima com destino ao Amazonas e a São Paulo".

O silenciamento discursivo excludente demarca a ideologia (Bourdieu, 1998), impõe o medo (Bauman, 2016), diferencia o nós e o outro (Foucault, 1997), os dominantes e os dominados (Weber, 2004/1922). Este "regime do olhar" perpetua um discurso de

\footnotetext{
${ }^{18}$ Filhos da imigração: em Roraima, 150 venezuelanas deram à luz em janeiro (2018, 20 de fevereiro). Jornal Nacional. Retirado de https://globoplay.globo.com/v/6519034/programa/

${ }^{19}$ Governo brasileiro vai transferir de RR para outros estados imigrantes venezuelanos $(2018,21$ de fevereiro). Jornal Nacional. Retirado de https://globoplay.globo.com/v/6522041/programa/

${ }^{20}$ A OEA pede que Venezuela adie as eleições presidenciais $(2018,23$ de fevereiro). Jornal Nacional. Retirado de https:// globoplay.globo.com/v/6528438/programa/

${ }^{21}$ Exército e Força Nacional controlam entrada de venezuelanos na região Norte (2018, 26 de fereveiro). Jornal Nacional. Retirado de https://globoplay.globo.com/v/6534599/programa/
} 
não aceitação e impossibilidades de convivência que se processa por meio da sensibilização focada na unidade, e não na alteridade (Martins, 2011, 2019).

Casos de sarampo em venezuelanos voltam a ser noticiados em 28/02/201822: já são seis os casos confirmados em Roraima, principalmente em crianças. O JN apresenta outros números, ressaltando que a campanha de vacinação será antecipada e priorizará imigrantes venezuelanos, para evitar um surto da doença "como o que ocorreu no país deles".

O noticiário de março veicula três notas e uma reportagem. Em 01/03/201823, aborda o adiamento das eleições presidenciais para a segunda quinzena de maio, sem a presença dos dois maiores líderes rivais, impedidos por Maduro de participar. Opositores convocaram boicote às eleições. No dia seguinte, $02 / 03 / 2018^{24}$, outra nota pelada relata morte de criança de quatro anos, cujo atestado de óbito indicou pneumonia, infecção generalizada e desnutrição grave. Este era um dos 12 casos suspeitos. As autoridades já confirmaram seis casos de sarampo em crianças venezuelanas, afirma a matéria.

Em reportagem do dia 10/03/2018 25, o tema é destaque na abertura do JN: «começa a campanha de vacinação contra o sarampo em Roraima. O Estado tem oito casos confirmados. Todos em venezuelanos". Campanha foi antecipada por causa do surto entre venezuelanos que estão no Estado e que não tinham acesso a vacinas no seu país de origem. Outros 38 casos suspeitos de sarampo estão sendo investigados. O Brasil está montando barreira sanitária para conter surto. Brasil não registrava casos de sarampo desde 2015. Ao final, a reportagem informa que, entre janeiro e fevereiro de 2018, 24.466 venezuelanos pediram para entrar no Brasil pelo posto da Polícia Federal de Roraima número quase três vezes maior do que no mesmo período de 2017.

Por fim, uma nota coberta de $20 / 03 / 2018^{26}$, relata em 26 segundos ações de moradores de Mucajaí, Roraima, que invadiram um prédio ocupado por venezuelanos, expulsando 50 imigrantes e queimando seus pertences, em protesto pelo assassinato de um morador, que teria sido morto por um venezuelano durante uma tentativa de assalto. Manifestantes contrários à imigração fecharam a rodovia que liga Brasil a Venezuela e exigiram fechamento das fronteiras.

Nas matérias apresentadas pelo JN, a desinformação é gerada pela carência de dados confiáveis, referentes ao atual processo de migração venezuelana no Brasil, justificado pela falta de controle efetivo de entradas e saídas de cidadãos venezuelanos na fronteira com o Estado de Roraima, principalmente a partir da crise econômica do país

\footnotetext{
${ }^{22}$ Já são seis os casos confirmados de sarampo em crianças venezuelanas em Roraima $(2018,28$ de fevereiro). Jornal $\mathrm{Na}$ cional. Retirado de https://globoplay.globo.com/v/6540991/programa/

${ }^{23}$ Venezuela adia eleições presidenciais (2018, 1 de março). Jornal Nacional. Retirado de https://globoplay.globo. $\mathrm{com} / \mathrm{v} / 6544191 /$ programa/

${ }^{24}$ Criança venezuelana com suspeita de sarampo morre em Boa Vista (2018, 2 de março). Jornal Nacional. Retirado de https://globoplay.globo.com/v/6547533/programa/

${ }^{25}$ Começa a campanha de vacinação contra o sarampo em Roraima (2018, 10 de março). Jornal Nacional. Retirado de https://globoplay.globo.com/v/6569499/programa/

${ }^{26}$ Grupo expulsa venezuelanos em Roraima (2018, 20 de março). Jornal Nacional. Retirado de https://globoplay.globo. com/v/6595539/programa/
} 
vizinho, momento em que muitos venezuelanos cruzavam a fronteira para comprar alimentos e produtos básicos, por preços mais acessíveis.

\section{REFLEX̃̃es ACERCA DO DISCURSO DO JORNAL NACIONAL}

Nas edições de 26/01, 19 e 26/02, o Jornal Nacional indica o governo de Maduro como responsável pela dimensão da crise, excluindo fatores globais e intervenções estrangeiras. Mas não são apresentadas fontes oficias do governo venezuelano, nem contrapontos sobre a situação política. As únicas fontes disponíveis são de opositores de Maduro, assim como dos países dominantes da OEA.

Das matérias analisadas neste recorte, depreendemos que o JN elabora representações sociais dos outros e de si, mediadas por estratégias simbólicas, que vão gerar efeitos sociais, ao interferir na construção de outras visões de mundo e no "inconsciente cultural", internalizando e reproduzindo valores, perpetuando relações de dominação (Bourdieu, 1989).

Em 20 de março de 2018, o JN cita que a crise foi agravada pela queda do preço internacional do petróleo. Não há referência contextual temporal anterior a esta. Em nenhum momento, o JN retoma dados do relatório da ONU (Jahan, 2017), até então o mais recente, sobre os progressos daquele país quanto ao Índice de Desenvolvimento Humano (IDH) nos últimos anos, por exemplo. O IDH da Venezuela estava próximo ao do Brasil, porém à frente. Não há menção à participação de multinacionais no mercado petrolífero da Venezuela, nem às tentativas de interferência norte-americana na política venezuelana, nem às sanções econômicas, nem tampouco à conturbada luta de Chávez e Maduro contra o imperialismo dos EUA, e destes contra o socialismo (Lopes, 2013; Sousa Santos, 2017).

Não faltam posicionamentos críticos do $J N$ às violações dos direitos humanos em matérias cujas fontes são representantes da ONU, Mercosul, Espanha, EUA, Brasil, Argentina, Chile. São silenciados os discursos de aliados do governo Maduro, como Nicarágua, El Salvador, Equador, e demarcados posicionamentos contrários à política de Nicolás Maduro.

As matérias de caráter humanista descrevem situações degradantes nos centros de acolhimento, assim como a morosidade na constituição do processo que lhes garanta condições de iniciar a construção de uma vida digna como refugiados. O funcionamento do processo de interiorização, ou seja, o processo de envio de imigrantes a outros estados, não é esclarecido pelo JN. A presença de refugiados enquanto fontes é significativa. Os seus depoimentos são utilizados para frisar o ponto de vista do JN sobre a Venezuela e seu modelo político. Dificilmente, as fontes são representantes de um contraponto. A expressividade de venezuelanos como fontes reforça a ideia de que são atores sociais excluídos e desempoderados pelas estruturas socialistas de Maduro, e que veem uma chance no modelo político-econômico brasileiro. A vinda dos migrantes e refugiados é marcada pelo JN como causa da desestabilidade da ordem, até então existente no norte do Brasil. 
Os brasileiros de Roraima são representados como generosos, exemplares, responsáveis por organizar o caos gerado pelo socialismo de Nicolás Maduro. No entanto, em meio à solidariedade da população de Boa Vista, são denunciados pelo JN ataques de brasileiros contrários à imigração. $O$ jornal narra a perversidade com que os refugiados e migrantes são tratados e "administrados" pelos governos, segundo a lógica da mercadoria, a partir do cadastramento, controle, realocação, redistribuição.

A identidade é um lugar que se assume, uma costura de posição e contexto, e não uma essência ou substância. As identidades não estão vinculadas a lugares e tradições de tempos específicos; são fluidas e híbridas, segundo Hall (2003). É a "presença (do outro) que me põe em xeque", que me força a pensar, assinala Levinas (1961/2002). É pela diferença do outro que me construo como eu mesmo. Diferir é distinguir-se, afirma Descombes (1998). A diferença constrói a identidade, "tornando objetos e seres diferenciáveis e, portanto, reconhecíveis em sua individualidade", diz Luiz lasbeck (2009, pp. 97-98) citando Heráclito, porque "a diferença (o conflito, a polêmica) é a origem de todas as coisas. Ou seja, é da divergência instaurada pelas diferenças que surge a multiplicidade das possibilidades". Essa visão afasta o medo.

Os outros neste estudo são os venezuelanos, imigrantes, refugiados, requerentes de asilo, é a Venezuela socialista. O nós representa o Brasil capitalista, que deve fugir das ameaças da esquerda. Os outros são aqueles cuja subjetividade é problematizável e cuja existência ocorre, como escreveu Bourdieu $(1989,1998)$, a partir do momento em que se é nomeado.

A representação dos cenários da "crise dos refugiados" venezuelanos opera através do poder simbólico, que legitima a construção da realidade, tendendo a estabelecer um sentido imediato do mundo (Bourdieu, 1989). Estas representações sociais dos outros e de si, mediadas por estratégias simbólicas, geram efeitos sociais, ao interferir na construção de outras visões de mundo no "inconsciente cultural", quer internalizando e reproduzindo valores, quer perpetuando relações de dominação. Pelo lado subjetivo, a percepção deste fenômeno migratório é "produto das lutas simbólicas anteriores e exprime, de forma mais ou menos transformada, o estado das relações de força" (Bourdieu, 1989, pp. 139-140).

$\mathrm{Na}$ amostra selecionada, imperam dados sobre a chegada de imigrantes, sobre a paralisia do governo brasileiro diante dos fatos, e sobre aumento de casos de sarampo entre a população. O JN não propõe alternativas ao "problema". As ações explicitadas do governo federal demonstram que a questão deve ser resolvida por Roraima. As ações da esfera pública federal quanto à interiorização destes imigrantes não foram apoiadas nem questionadas pelo JN. Seu consentimento corrobora com mecanismos de seleção de imigrantes aptos (ou dispostos?) a compor a população de outros estados.

A chegada dos imigrantes é narrada como uma ameaça à normalidade e à estabilidade, que requer o uso do poder e da força do governo federal em Roraima. O JN propaga o sentimento de insegurança e caos, oferecendo números como entidades absolutas, sem o devido contexto. A prevalência dos interesses nacionais constrói um discurso 
perigoso, de crise constante, que pode levar à xenofobia. Muitos cidadãos rejeitam refugiados por medo de perder suas posições sociais, trabalho, qualidade de atendimento na saúde. É o medo do outro que não somos nós, medo da diferença, como se esta colocasse-nos em risco. Não é mais somente a cor, o idioma, a raça do outro, que incomodam. O medo relaciona-se com a perda daquilo de que os imigrantes estão à procura: a dignidade de poder fazer suas escolhas e a segurança da aparente estabilidade.

O uso recorrente da expressão "onda de imigrantes venezuelanos" pelo Jornal Nacional integra uma estratégia de silenciamento, que substitui as pautas de interesse político e nacional por escolhas editoriais. Esta afirmação pode ser comprovada pela ínfima presença no noticiário de dados publicados por instituições públicas de pesquisa, referentes ao uso dos serviços públicos por venezuelanos em Roraima, assim como à posição do Brasil no cenário global de acolhimento de pessoas em situação de vulnerabilidade (Simões, Cavalcanti, Oliveira, Moreira \& Camargo, 2017).

Em Bourdieu, as noções de campo e habitus, assim como as reflexões de Foucault sobre o discurso, permitem compreender as notícias como resultantes de um processo de construção simbólica, no qual estão envolvidas diferentes motivações, que evidenciam os silenciamentos e os pretextos que levam aos enfoques no acontecimento, e não na problemática.

\section{CONSIDERAÇões FINAIS}

À luz da Sociologia compreensiva e da Filosofia, analisámos os nós cegos da "crise dos refugiados", presentes nas práticas discursivas do JN. A constatação dos silenciamentos permitiu perceber os mecanismos de exclusão e a "domesticação dos dominados" (Weber, 2004/1922), ocultos à primeira vista.

As narrativas do JN não contribuem para a coabitação das diferenças. O campo midiático, econômico e político, como pilares da sociedade monetarizada, centrados na unidade que assimila a diferença, domina os subalternos. Este "regime da unidade" funciona por meio da analogia e da correspondência, lembra Martins (2011, p. 46): o que nos for estranho não é legítimo nem pode ser legitimado. Anula-se a diferença pela impossibilidade de co-existência, o que nos leva à "fragmentação da experiência".

A perpetuação do regime discursivo acerca do outro funciona como mecanismo de exclusão, ou então, de domesticação - ambos exercícios do poder e da vontade de verdade, geradores de medos e inseguranças, enquanto criam, ou então mantêm, "corpos-dóceis" (Foucault, 1970, 1988, 1997). Do que se trata, então, é do homem inseguro, dependente, que vive um simulacro de autonomia e participação via consumo. Simulacro de resistência, talvez, mas que serve para que o dominante continue dominando, na visão de Foucault. É bem verdade que os bons governantes amam a santa indignação dos governados, desde que ela permaneça lírica. Para que o poder prospere, mantém-se, pois, esta resistência, no dizer de Martins (2011), que torna o homem cada vez mais dependente do seu emprego e salário, para sobreviver e bancar outras dependências, como a tecnológica, a sensorial e a erótica. 
Uma vez legitimado e reconhecido como um locutor confiável pela sociedade, o JN tem autoridade para elaborar percepções de mundo que poderão constituir a visão dos seus leitores. É o funcionamento do campo, do habitus e do poder simbólico, de que tratou Bourdieu. O JN passa-nos uma leitura de que o Brasil estaria em outro status de civilização em relação à Venezuela. Apaga seu próprio histórico colonial, de país em desenvolvimento, para colocar-se num patamar de superioridade, por seu modo de produção capitalista em oposição ao socialismo de Maduro. Uma visão distorcida, que reforça a impossibilidade da diferença. Ambos os países são coloniais. O Brasil também enfrenta um momento de instabilidade político-econômica, mas, ainda assim, é melhor opção, no ponto de vista dos imigrantes venezuelanos. No momento das narrativas, - JN apaga a crise brasileira. Foca em dados que podem gerar medos e receios nos brasileiros, como ter de ceder espaço aos venezuelanos no mercado de trabalho e nos serviços públicos de saúde.

"Dar voz" aos imigrantes e refugiados não é sinônimo de respeito e reconhecimento da sua alteridade. A mídia é um campo legítimo para as disputas ideológicas. $\mathrm{O}$ IN defende suas visões de mundo nas narrativas sobre os venezuelanos, num discurso nacionalista, colonizador, no qual reverbera a voz do neoliberalismo e do capitalismo como única condição de desenvolvimento social.

\section{REFERÊNCIAS}

Acnur. Convenção Relativa ao Estatuto dos Refugiados. Retirado de http://www.acnur.org/t3/fileadmin/ Documentos/portugues/BDL/Convencao_relativa_ao_Estatuto_dos_Refugiados.pdf

Acnur. O que é a Convenção de 1951? Retirado de http://www.acnur.org/portugues/ informacao-geral/o-que-e-a-convencao-de-1951/

Bauman, Z. (2004). Vidas desperdiçadas. Rio de Janeiro: Zahar.

Bauman, Z. (2016, 13 de outubro). Why the world fears refugees. Retirado de https://www.youtube.com/ watch?v=_Qlv8pqtTss

Bauman, Z. (2017). Estranhos à nossa porta. Rio de Janeiro: Zahar.

Berkowitz, D. (Ed.) (1997). Social meanings of news. A text-reader. Thousand Oaks: Sage Publications.

Botelho, J. C. A. (2008). A democracia na venezuela da era chavista. Aurora, 1(2), 18-25. Retirado de http:// www2.marilia.unesp.br/revistas/index.php/aurora/article/view/1174

Bourdieu, P. (1978). Capital simbólico e classes sociais. Novos estudos - Cebrap, 96. Retirado de http://www. scielo.br/scielo.php?script=sci_arttext\&pid=S0101-33002013000200008\#nt

Bourdieu, P. (1989). O poder simbólico. Rio de Janeiro: Bertrand Brasil.

Bourdieu, P. (1998). Prefácio. In A. Sayad (Ed.), A imigração ou os paradoxos da alteridade (pp. 9-12). São Paulo: Editora da Universidade de São Paulo.

Breed, W. (1997). Social control in the news room. In D. Berkowitz (Ed.), Social meanings of news. A text-reader (pp. 107-122). Thousand Oaks: Sage Publications. 
Buarque, D. (2016, 11 de agosto). Pesquisa revela alta rejeição a refugiados e imigrantes no mundo. Folha de São Paulo. Retirado de http://www1.folha.uol.com.br/mundo/2016/08/1801673-pesquisa-revela-altarejeicao-a-refugiados-e-imigrantes-no-mundo.shtml

Charleaux, J. P. (2018, 14 de fevereiro). Como o Brasil lida com a imigração. Nexo Jornal. Retirado de https://www.nexojornal.com.br/expresso/2018/02/14/ Como-o-Brasil-lida-com-a-imigra\%C3\%A7\%C3\%A3o-venezuelana

Costa, E. \& Brandão, I. (2018, 2 de março). Rota da fome. G1 Roraima. Retirado de https://g1.globo.com/rr/ roraima/noticia/rota-da-fome-o-caminho-dos-venezuelanos-que-enfrentam-perigo-falta-de-comida-e-deagua-para-chegar-a-boa-vista.ghtml

Descombes, V. (1998). Lo mismo y lo outro. Cuarenta y cinco años de filosofía francesa (1933-1978). Madrid: Catedra.

Eagleton, T. (1997). Ideología. Uma introducción. Barcelona: Paidós.

Foucault, M. (1970). The order of things: na archaeology of the Human Sciences. Londres: Tavistock.

Foucault, M. (1988). Microfísica do poder. Rio de Janeiro: Graal.

Foucault, M. (1997). A ordem do discurso. Lisboa: Relógio D Água.

Hall, S. (2001). A identidade cultural na pós-modernidade. Rio de Janeiro: DP\&A Editora.

Hall, S. (2003). Da diáspora. Identidades e mediações culturais. Belo Horizonte: UFMG.

lasbeck, L. C. A. (2009). Diferença. In C. M. Filho (Ed.), Dicionário de Comunicação (pp. 97-98). São Paulo: Paulus.

Jahan, S. (2017). Relatório de desenvolvimento humano (RDH) 2016. Nova lorque: Programa das Nações Unidas para o Desenvolvimento (PNUD). Retirado de http://www.br.undp.org/content/brazil/pt/home/ idho/relatorios-de-desenvolvimento-humano/rdhs-globais.html

Levinas, E. (1961/2002). Totalidad e infinito. Ensayo sobre la exterioridade. Salamanca: Ediciones Sígueme.

Lopes, M. O. (2013). Balanço teórico da Venezuela bolivariana. In Anais V Simpósio Internacional Lutas Sociais na América Latina: revoluções nas Américas: passado, presente e futuro (pp. 11-25). Londrina, Brasil: grupo de Estudos de Políticas da América Latina. Retirado de http://www.uel.br/grupo-pesquisa/gepal/v2_ mariana_GVI.pdf

Malik, K. (2014). Human development report. Nova lorque: Programa das Nações Unidas para o Desenvolvimento (PNUD). Retirado de http://hdr.undp.org/sites/default/files/hdr2014_pt_web.pdf

Martins, M. L. (2011). Crise no castelo da cultura: das estrelas para os ecrãs. Coimbra: Grácio Editor.

Martins, M. L. (2015). Os Estudos Culturais como novas Humanidades. Revista Lusófona de Estudos Culturais / Lusophone Journal of Cultural Studies, 3(1), 341-361. Retirado de http://hdl.handle.net/1822/40655

Martins, M. L. (2019). A “crise dos refugiados" na Europa - entre totalidade e infinito. Comunicação $e$ Sociedade. [vol. especial], 21-36. https://doi.org/10.17231/comsoc.0(2019).3058

Ministério da Justiça (2017a). Refúgio em números. Retirado de http://www.justica.gov.br/news/brasil-temaumento-de-12-no-numero-de-refugiados-em-2016/20062017_refugio-em-numeros-2010-2016.pdf/view

Ministério da Justiça. (2017b). Refúgio em números. Retirado de http://www.acnur.org/portugues/wpcontent/uploads/2018/04/refugio-em-numeros_1104.pdf 
ONU ataca 'demonização' de migrantes após pesquisa mostrar rejeição a eles (2016, 11 de agosto). Folha de São Paulo. Retirado de http://www1.folha.uol.com.br/mundo/2016/08/1802265-onu-atacademonizacao-de-migrantes-apos-pesquisa-mostrar-rejeicao-a-eles.shtml

Organização dos Estados Americanos (OEA) (2017). Institucionalidad democrática, estado de derecho y derechos humanos en Venezuela: Informe de país. Venezuela: Comisión Interamericana de Derechos Humanos. Retirado de http://www.oas.org/es/cidh/informes/pdfs/Venezuela2018-es.pdf

Schudson, M. (1986). What time means in a news story (Occasional Paper No. 4). Nova lorque: Columbia University, Gannett Center for Media.

Schudson, M. (1988). Por que é que as notícias são como são. Comunicação e Linguagens, 8, 17-27.

Schurster, K. \& Araujo, R. (Ed.) (2015). A era Chávez e a Venezuela no tempo presente. Rio de Janeiro: Autografia.

Simões, G., Cavalcanti, L., Oliveira, T., Moreira, E. \& Camargo, J. (2017). Perfil socidemográfico e laboral da imigração venezuelana no Brasil. Brasília: Conselho Nacional de Imigração. Retirado de http://obmigra. mte.gov.br/index.php/publicacoes-obmigra

Sousa Santos, B. (2017, 28 de julho). Em defesa da Venezuela. Brasil de Fato. Retirado de https://www. brasildefato.com.br/2017/07/28/artigo-or-em-defesa-da-venezuela/

Sousa, J. P. (2000). As notícias e os seus efeitos. Coimbra: Minerva Editora.

Traquina, N. (2001). O estudo do jornalismo no século XX. São Leopoldo: Editora Unisinos.

Tuchman, G. (1978). Making news. A study in the construction of reality. Nova lorque: The Free Press.

Weber, M. (2004/1922). Economia e sociedade: fundamentos da sociologia compreensiva. V. 2. Distrito Federal: Editora Universidade de Brasília. Retirado de https://ayanrafael.files.wordpress.com/2011/08/weber-meconomia-e-sociedade-fundamentos-da-sociologia-compreensiva-volume-2.pdf

\section{NOTAS BIOGRÁFICAS}

Valéria Marcondes é docente na Universidade do Oeste de Santa Catarina (Santa Catarina, Brasil), na Faculdade de Ciências Sociais Aplicadas (Facisa), Curso de Jornalismo. Doutora em Comunicação Social pela Pontifícia Universidade Católica do Rio Grande do Sul, com bolsa Capes (2011). Pós-doutora pela Universidade do Minho (Braga, Portugal), 2017, sob supervisão de Moisés de Lemos Martins. Participou do Programa de Doutorado com Estágio no Exterior (PDEE), em 2009, na Universidade Autônoma de Barcelona (UAB), com bolsa Capes. Mestre em Comunicação Social pela Pontifícia Universidade Católica do Rio Grande do Sul, com bolsa Capes (2006), bolsa CNPq. Jornalista pela Universidade de Passo Fundo (2003). Diretora de Pesquisa e Pós-graduação stricto sensu na Unochapecó (2012-2016).

Email: leriamarcondes@hotmail.com

Morada: Rodovia BR 282, KM 528, Acesso Linha Limeira, 199, CEP 89.825-000 Xaxim/ SC, Brasil 
Moisés de Lemos Martins é Professor Catedrático do Departamento de Ciências da Comunicação da Universidade do Minho. Dirige o Centro de Estudos de Comunicação e Sociedade (CECS), que fundou em 2001. É Diretor da revista Comunicação e Sociedade e também da Revista Lusófona de Estudos Culturais (RLEC). Doutorado pela Universidade de Estrasburgo em Ciências Sociais (na especialidade de Sociologia), em 1984, tem publicado, no âmbito da Sociologia da Cultura, Semiótica Social, Sociologia da Comunicação, Semiótica Visual, Comunicação Intercultural, Estudos Lusófonos. Dirigiu durante dez anos o Instituto de Ciências Sociais da Universidade do Minho (de 1996 a 2000, e de 2004 a 2010). Em 2016, a Universidade do Minho concedeu-lhe o Prémio do Mérito Científico. Destacam-se as seguintes obras: Crise no Castelo da Cultura. Das Estrelas para os Ecrãs (2017, 2011); A Linguagem, a Verdade e o Poder. Ensaio de Semiótica Social (2017, 2002); O Olho de Deus no Discurso Salazarista (2016, 1990); A Internacionalização das Comunidades Lusófonas e Ibero-Americanas de Ciências Sociais e Humanas. O Caso das Ciências da Comunicação (2017); Lusofonia e Interculturalidade - Promessa e Travessia (2015).

ORCID: https://orcid.org/0000-0003-3072-2904

Email: moisesm@ics.uminho.pt

Moarada: Centro de Estudos de Comunicação e Sociedade, Instituto de Ciências Sociais, Universidade do Minho, campus de Gualtar, 4710-057 Braga, Portugal

Submetido: 12.05.2019

Aceite: 12.09.2019 